\title{
JOB SATISFACTION OF HEALTH CARE WORKERS IN THE SACRED PLACES DURING HAJJ SEASON 1429H (2008G).
}

\author{
By \\ Elshinnawey M.A. * and Othman N.A.** \\ From \\ *Community, Occupational and Environmental medicine Dept. Suez Canal University (Egypt) \\ **Information center Ministry of Health (Saudi Arabia)
}

\begin{abstract}
:
Background: Health care of pilgrims is a major priority for the government of Kingdom of Saudi Arabia (KSA) and measurement of job satisfaction of health care workers (hcw) is an important step for planning for increasing productivity and quality of care. Aim: This study aimed at assessing the level of job satisfaction and its determinants in hcw involved in health care of pilgrims in the sacred places in Makkah, KSA. Materials and Methods: through a cross sectional study, a sample of $584 \mathrm{hcw}$ were examined according to a structured questionnaire and a modified IDAK group job satisfaction scale. Hcw were classified into satisfied and unsatisfied according to tested cutoff point. Results: The rate of job satisfaction was $83.73 \%$. Job satisfaction was significantly increased in older hcw, females, Non-Saudis, working in Arafat area, and frequently participating how in hajj seasons. Job retention was significantly expected to increase by $76.03 \%$ among satisfied, older age groups, Non-Saudis, preventive teamwork and frequently participating how in Hajj seasons. Conclusion: Rate of job satisfaction in hcw in Hajj was high in comparison to other common health care situations. Job retention rate was accordingly expected to be high but lower than satisfaction rate. Recommendations: Younger, males, Saudis, new participants or with lack of previous participations and low paid how must be targeted by research, training and education to enhance their job satisfaction and job retention before going to work in Hajj.
\end{abstract}

Key words: Job satisfaction-health care workers- Hajj - Saudi Arabia 


\section{Introduction:}

Hajj is an annual Major event when about 2 million pilgrims (Annual statistical report of Hajj; 2007) gather in a limited time and very limited areas. This event is a top priority to the government of Saudi Arabia to facilitate the performance of Hajj for all pilgrims. Healthcare services are provided mainly by the Saudi Ministry of Health during Hajj season, including preventive and curative services which are operated by about 10,000 Health care workers (hcw) who are recruited from the different regional health sectors of Ministry of Health. This staff strengthens the workforce of the existing permanent facilities in Madinah, Makkah and to staff of the 7 seasonal hospitals and 84 primary healthcare centers in Mina and Arafat including the preventive activities.

Ministry of health is always looking forward to improve the services during Hajj in order to optimize for the services delivered to the pilgrims and in this trend, evaluating for the satisfaction of the how during Hajj may be helpful as one of the most important aspects in this improvement mechanism.

Hcw were the corner stone in the integrity of the healthcare system during Hajj and their satisfaction is definitely one of the determinants of productivity. General perception is that how compensation (high pay and benefits) is the dominating factor in their satisfaction, but there might be much less expensive ways to create a greater satisfaction among them during Hajj. For example, a good relationship with the immediate supervisors and colleagues is a motivating factor for the workers regardless of the financial benefits (Lehmann et al; 2005).

Creating a work environment that results in high how satisfaction during Hajj is not impossible and trying to know the factors responsible for creating such environment can be the first step towards achieving this objective.

\section{Objective:}

To assess the level of job satisfaction and its determinants in how involved in health care of pilgrims in the sacred places in Makkah, Saudi Arabia (Hajj period)

\section{Subjects and Methodology:}

\section{Study design:}

A cross-sectional study was conducted aiming at assessing the satisfaction level and its determining factors among Ministry of Health workers during Hajj period in the sacred places (Mina, Makkah \& Arafat). 


\section{Study population:}

All workers in Ministry of Health providing preventive and curative health services during Hajj season were the sampling frame. The total number of employees during Hajj this year was 9,654, about 6200 were in Mina and Arafat in 7 hospitals and 84 primary centers (Records of human resources working in Hajj; 2008). The average number of workers in each hospital was 250 , while the average in primary health care centers of Mina was 50 and in Arafat was 30 .

\section{Sample size and Sampling techniques:}

The sample size was calculated according to the main aim of the study. Figures of job satisfaction in the same conditions were not available, so, figures near to the study backgrounds were selected to determine the sample size. Previous studies revealed a dissatisfaction rate of $25 \%$ (Canadian National physician survey; 2008). Accordingly, assuming dissatisfaction prevalence of $25 \%$ with a precision of $4 \%$ and design effect of 2 at $95 \%$ confidence limits, a sample size of 550 was estimated by using Epi info soft ware for sample size (Epi info version $6.04,2001)$. Ten percent was added to overcome drop out, so the total estimated size were $605 \mathrm{hcw}$. The response rate were $96.5 \%$ so the total examined sample were 584 hew.
A multistage cluster sampling technique was used when the healthcare facilities were the primary sampling unit and the hcw were considered the secondary sampling unit.

Seven hospitals and 22 Primary health care centers in Makkah, Mina and Arafat were included in the study. Within each hospital or primary health care center, the hcw were sampled by simple random technique and the number of the sample was proportionate to the number of workers in each site of care. By this technique the total selected sample was 584 hcw.

\section{Data collection:}

\section{Tool of data collection:}

The use of traditional job satisfaction scales to assess job satisfaction in hajj is non-applicable due to causes related to nature of health care in Hajj, but the main dimensions of measuring job satisfaction were considered. These factors include:

1- The duration of health care is short (about one month)

2- The flow rate is very high

3- The work sites are seasonal not permanent.

4- Health care workers are from different regions in Saudi Arabia and from different nationalities. 
5- Patients come from different countries.

Due to these factors, a self-administered questionnaire and IDAK group Job Satisfaction scale (IDAK Group, 2005) was designed to assess job satisfaction and its determinants in those workers. The questionnaire were given in Arabic and English format and included:

1. Demographic data.

2. Ways of participation in Hajj.

3. Transportation from their region and arrival in Makkah.

4. Housing and recreation.

5. Organizational background

6. Work Load.

7. Financial aspect.

8. Participation in the next Hajj.

Instructions were given to targeted workers before filling questionnaire. A brief notes were written to them to facilitate their answers. The questionnaires were filled by the workers at the end of Hajj duty immediately before they receive their dutycompletion certificates.

\section{Data Management and analysis:}

After data collection, questionnaires were reviewed and entered into a prepared data entry screen on SPSS version 15. Soft cleaning was done and data entry error managed by referring to questionnaire. Descriptive statistics were done to describe personal characteristics. The total scores of satisfaction were calculated. A tested cut off point were used to define satisfied from unsatisfied hcw (Ruwoldt et al; 2007). Chi square test were used to test the association between job satisfaction and the suspected determinants.

\section{Results:}

Table 1 shows the personal characteristics of the study sample. The highest number was for 30 - 39 age group, while the lowest was for $50-60$ age group. Males $(73.8 \%)$ were higher than females $(26.2 \%)$. Saudis $(57.19 \%)$ were slightly higher than Non-Saudis $(42.81 \%)$. Administrative personnel $(40.41 \%)$ and physicians $(24.83 \%)$ were the highest occupational groups while the lowest were for pharmacists $(5.65 \%)$.

The satisfied hew constitute $83.73 \%$. It differs according to age, sex, nationality and type of the job. The rates of job satisfaction were significantly increased with the increasing age group reaching its highest for 50 - 60 age group (91.67\%). Satisfied females $(90.85 \%)$ were significantly higher than satisfied males (81.215), while Saudis satisfaction $(77.84 \%)$ were significantly 
lower than Non-Saudis (91.60\%). The rates of job satisfaction among different job titles were not significantly different.

The association between job satisfaction and other specific important variables were shown in table (3). Significantly different rates of job satisfaction were detected in work areas in hajj. The highest rate of satisfaction was detected for how in Arafat $(91.96 \%)$ while the lowest was for how in Makkah (75.57\%). The rate of job satisfaction was increased according to the increase in number of previous participations in hajj with the highest rate in five times participations $(92.74 \%)$. The readiness to participate in the next hajj seasons and enough payment were also associated with significant increase of rates of satisfactions by $(94.14 \%)(95.88 \%)$ respectively. The rate of job satisfaction insignificantly varies according to the setting of health care and the region which the how came from.

Regarding factors affecting job retention (table 4), willing to participate next hajj seasons were expected to be significantly higher in older age groups and nonSaudis. It also significantly associated with higher numbers of participations and higher rates of job satisfaction. A likely significant association ( $\mathrm{p}=0.05$ )was detected between job retention and sex being more in females $(81.05 \%)$ than in males $(74.25 \%)$ and health care setting being more in preventive than curative. Job title, work area and the region which the how came from were not significantly associated with job retention. 
Table (1): Socio-demographic characteristics of the study population

\begin{tabular}{|c|c|c|c|}
\hline \multicolumn{2}{|c|}{ Variables } & No. & $\%$ \\
\hline \multirow{4}{*}{ Age group } & $20-29$ & 149 & 25.51 \\
\cline { 2 - 4 } & $30-39$ & 207 & 35.45 \\
\cline { 2 - 4 } & $40-49$ & 168 & 28.77 \\
\cline { 2 - 4 } & $50-60$ & 60 & 10.27 \\
\cline { 2 - 4 } & Total & $\mathbf{5 8 4}$ & $\mathbf{1 0 0 . 0 0}$ \\
\hline \multirow{4}{*}{ Sex } & Male & 431 & 73.80 \\
\cline { 2 - 4 } & Female & 153 & 26.20 \\
\cline { 2 - 4 } & Total & $\mathbf{5 8 4}$ & $\mathbf{1 0 0 . 0 0}$ \\
\hline \multirow{4}{*}{ Nationality } & Saudi & 334 & 57.19 \\
\cline { 2 - 4 } & Non-Saudi & 250 & 42.81 \\
\cline { 2 - 4 } & Total & $\mathbf{5 8 4}$ & $\mathbf{1 0 0 . 0 0}$ \\
\hline \multirow{5}{*}{ Job title } & Physician & 145 & 24.83 \\
\cline { 2 - 4 } & Pharmacist & 33 & 5.65 \\
\cline { 2 - 4 } & Nurse & 90 & 15.41 \\
\cline { 2 - 4 } & Administrator & 236 & 40.41 \\
\cline { 2 - 4 } & Technician & 80 & $\mathbf{1 0 0 . 0 0}$ \\
\cline { 2 - 4 } & Total & $\mathbf{5 8 4}$ & \\
\cline { 2 - 4 } & & & \\
\hline
\end{tabular}

Table (2): Association between socio-demographic characteristics and job satisfaction

\begin{tabular}{|c|c|c|c|c|c|c|c|}
\hline \multicolumn{2}{|c|}{ Variables } & \multicolumn{2}{c|}{ Satisfied } & \multicolumn{2}{c|}{ Not Satisfied } & \multicolumn{2}{c|}{ Total } \\
\cline { 2 - 8 } & $20-29$ & No. & $\%$ & No. & $\%$ & No. & $\%$ \\
\hline \multirow{4}{*}{ Age group* } & $30-39$ & 180 & 70.47 & 44 & 29.53 & 149 & 25.51 \\
\cline { 2 - 8 } & $40-49$ & 149 & 88.69 & 19 & 11.31 & 168 & 28.77 \\
\cline { 2 - 8 } & $50-60$ & 55 & 91.67 & 5 & 8.33 & 60 & 10.27 \\
\cline { 2 - 8 } & Total & $\mathbf{4 8 9}$ & $\mathbf{8 3 . 7 3}$ & $\mathbf{9 5}$ & $\mathbf{1 6 . 2 7}$ & $\mathbf{5 8 4}$ & $\mathbf{1 0 0 . 0 0}$ \\
\hline \multirow{5}{*}{ Sex* } & Male & 350 & 81.21 & 81 & 18.79 & 431 & 73.80 \\
\cline { 2 - 8 } & Female & 139 & 90.85 & 14 & 9.15 & 153 & 26.20 \\
\cline { 2 - 8 } & Total & $\mathbf{4 8 9}$ & $\mathbf{8 3 . 7 3}$ & $\mathbf{9 5}$ & $\mathbf{1 6 . 2 7}$ & $\mathbf{5 8 4}$ & $\mathbf{1 0 0 . 0 0}$ \\
\hline \multirow{4}{*}{ Nationality* } & Saudi & 260 & 77.84 & 74 & 22.16 & 334 & 57.19 \\
\cline { 2 - 8 } & Non-Saudi & 229 & 91.60 & 21 & 8.40 & 250 & 42.81 \\
\cline { 2 - 8 } & Total & $\mathbf{4 8 9}$ & $\mathbf{8 3 . 7 3}$ & $\mathbf{9 5}$ & $\mathbf{1 6 . 2 7}$ & $\mathbf{5 8 4}$ & $\mathbf{1 0 0 . 0 0}$ \\
\hline \multirow{5}{*}{ Job title } & Physician & 116 & 80.00 & 29 & 20.00 & 145 & 24.83 \\
\cline { 2 - 8 } & Pharmacist & 30 & 90.91 & 3 & 9.09 & 33 & 5.65 \\
\cline { 2 - 8 } & Nurse & 78 & 86.67 & 12 & 13.33 & 90 & 15.41 \\
\cline { 2 - 8 } & Administrator & 195 & 82.63 & 41 & 17.37 & 236 & 40.41 \\
\cline { 2 - 8 } & Technician & 70 & 87.50 & 10 & 12.50 & 80 & 13.70 \\
\cline { 2 - 8 } & Total & $\mathbf{4 8 9}$ & $\mathbf{8 3 . 7 3}$ & $\mathbf{9 5}$ & $\mathbf{1 6 . 2 7}$ & $\mathbf{5 8 4}$ & $\mathbf{1 0 0 . 0 0}$ \\
\hline
\end{tabular}


Table (3): Association between job satisfaction and suspected job characteristics

\begin{tabular}{|c|c|c|c|c|c|c|c|}
\hline \multirow{2}{*}{\multicolumn{2}{|c|}{ Variables }} & \multicolumn{2}{|c|}{ Satisfied } & \multicolumn{2}{|c|}{ Not Satisfied } & \multicolumn{2}{|c|}{ Total } \\
\hline & & $\mathrm{No}$ & $\%$ & $\mathrm{No}$ & $\%$ & $\mathrm{No}$ & $\%$ \\
\hline \multirow{4}{*}{ Work area* } & Arafat & 183 & 91.96 & 16 & 8.04 & 199 & 34.08 \\
\hline & Mina & 207 & 81.50 & 47 & 18.50 & 254 & 43.49 \\
\hline & Makkah & 99 & 75.57 & 32 & 24.43 & 131 & 22.43 \\
\hline & Total & 489 & 83.73 & 95 & 16.27 & 584 & 100 \\
\hline \multirow{4}{*}{ Setting of $\mathrm{HC}$} & Hospital & 286 & 81.48 & 65 & 18.52 & 351 & 60.1 \\
\hline & Primary HC & 132 & 85.16 & 23 & 14.84 & 155 & 26.54 \\
\hline & Preventive center & 71 & 91.03 & 7 & 8.97 & 78 & 13.36 \\
\hline & Total & 489 & 83.73 & 95 & 16.27 & 584 & 100 \\
\hline \multirow{3}{*}{ Region of hcw } & Riyadh region & 248 & 82.12 & 54 & 17.88 & 302 & 51.71 \\
\hline & Makkah region & 241 & 85.46 & 41 & 14.54 & 282 & 48.29 \\
\hline & Total & 489 & 83.73 & 95 & 16.27 & 584 & 100 \\
\hline \multirow{5}{*}{$\begin{array}{c}\text { Number of } \\
\text { participations* }\end{array}$} & $>1$ st time & 145 & 76.32 & 45 & 23.68 & 190 & 32.53 \\
\hline & 2 - 3 times & 124 & 81.58 & 28 & 18.42 & 152 & 26.03 \\
\hline & $4-5$ times & 85 & 88.54 & 11 & 11.46 & 96 & 16.44 \\
\hline & $>5$ times & 135 & 92.47 & 11 & 7.53 & 146 & 25 \\
\hline & Total & 489 & 83.73 & 95 & 16.27 & 584 & 100 \\
\hline \multirow{4}{*}{ Enough Payment?* } & Don't know & 75 & 77.32 & 22 & 22.68 & 97 & 16.61 \\
\hline & No & 251 & 79.18 & 66 & 20.82 & 317 & 54.28 \\
\hline & Yes & 163 & 95.88 & 7 & 4.12 & 170 & 29.11 \\
\hline & Total & 489 & 83.73 & 95 & 16.27 & 584 & 100.00 \\
\hline \multirow{3}{*}{$\begin{array}{c}\text { Participate next } \\
\text { year?* }\end{array}$} & No & 71 & 50.71 & 69 & 49.29 & 140 & 23.97 \\
\hline & Yes & 418 & 94.14 & 26 & 5.86 & 444 & 76.03 \\
\hline & Total & 489 & 83.73 & 95 & 16.27 & 584 & 100.00 \\
\hline
\end{tabular}

* Statistically significant 
Table (4) Suspected job retention factors in the study.

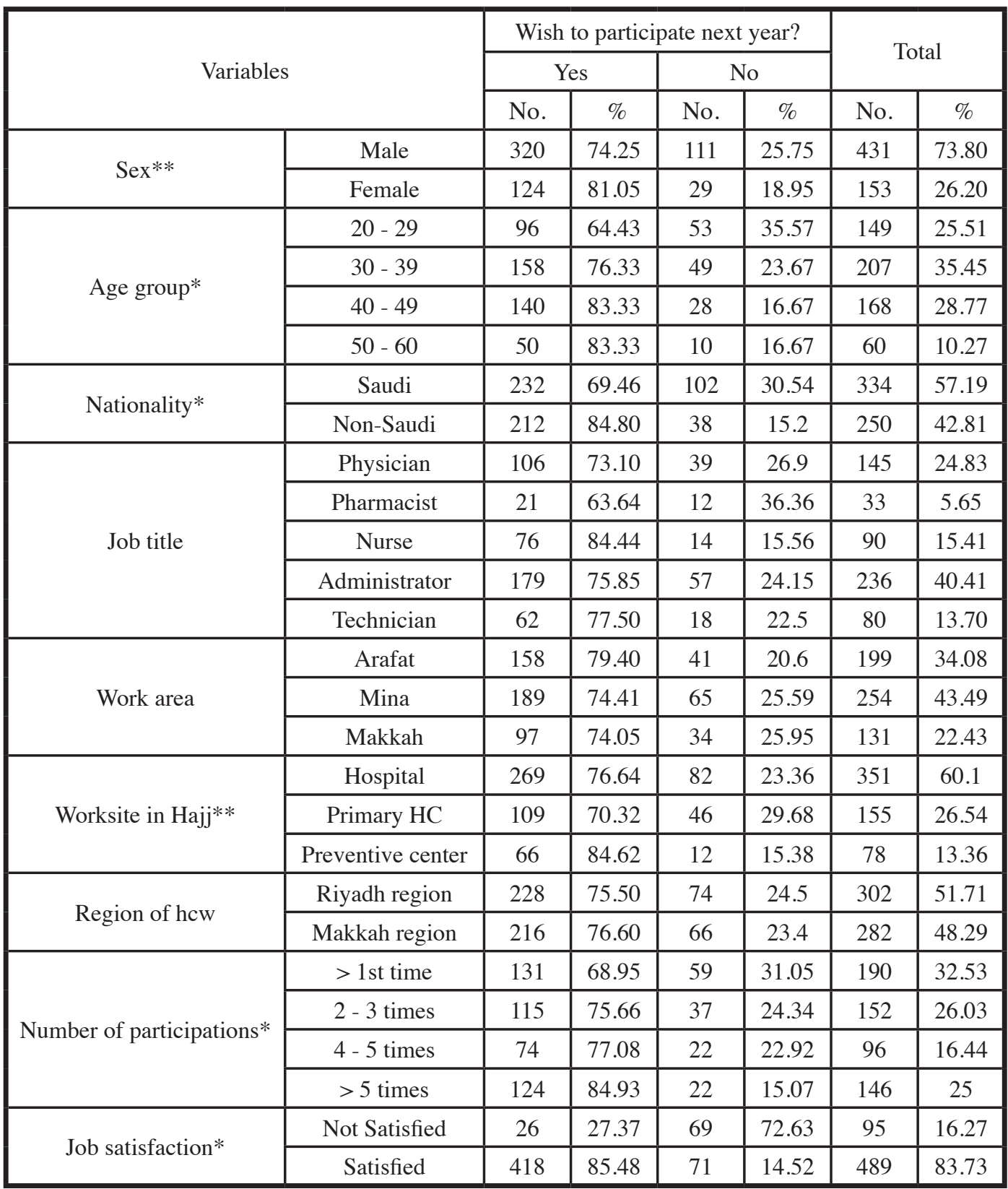

* Statistically significant $* *$ p value $=0.05$ 


\section{Discussion:}

Job satisfaction among how has received great attention recently (Leigh et al; 2002). Hcw who are satisfied with their careers are likely to provide better health care than dissatisfied how. Their satisfaction has been found to strongly correlate with patient satisfaction (Haas et al; 2000). High physician satisfaction is also likely to result from good outcomes with patients (Katz; 1999). Career satisfaction, therefore, may be an indirect measure of patient outcomes.

In Hajj, health care workers are faced by a high rates of consumers ( 2 million pilgrims) coming from different regions in the world, with different ages, sexes, nationalities, weather conditions, different risk factors with a hope of spending their Hajj rituals and adorations in good health. Due to these factors, health care workers may be exposed to high level of stress which may affect their satisfaction, productivity and quality of care.

This study tried to assess the level of job satisfaction and its determinants in how involved in health care in this major event.

In this study, the rate of job satisfaction $(83.73 \%)$ was higher than that detected by other studies in other situations (Kalantan et al; 1999, Leigh et al; 2002 and Canadian National physician survey; 2008).
Regarding personal factors, this study revealed that, the rate of satisfaction among the different age groups is increasing with the increasing age. These figures support previous studies (Pathman et al; 2002, Wetterneck; 2002 and Ejaz et al; 2008). Those studies indicated that, the older age groups are more experienced with life events than younger age groups and more trained to efficiently cope with different situations, whereas younger persons are less confident in facing life stressors given their relative lack of experience. Conversely, another study reported that age seems to lead to a significant tendency to decreased satisfaction as practitioners grow older (Sobreques et al; 2003).

The rate of satisfaction among females was higher than in males which in concordance with findings of (Jennifer; 2003 and Abdel-Rahman et al; 2008). They found higher levels of job satisfaction among female how than among males.

The rate of satisfaction among Saudis were lower than Non-Saudis which is not in concordance with (Pathman et al; 2002 and Al-Eisa et al; 2005). They revealed high rates of job satisfactions among natives than non-natives. In hajj higher rates of Non-Saudis satisfaction may be due to two factors: The first may be due to high financial compensation by KSA. The second 
factor may be due to nobleness and psychological support they get by serving pilgrims which is not available in their homes.

Job title in this study was not significantly associated with job satisfaction but a high rate of satisfaction was detected in all professions. These findings were supported by other studies (Al-Eisa et al; 2005 and Abdel-Rahman et al; 2008) but also against others (Bodur; 2002 and Joyce et al; 2003). The non-supporting literature related low satisfaction to organizational and financial factors.

Work area in this study may have an important role in job satisfaction. The highest rate of satisfaction was detected for Arafat how while the lowest was for Makkah area. This is may be due to short duration of working and staying in Arafat region in comparison to that of Mena and Makkah.

In this study, setting of health care was not significantly associated with job satisfaction but how in hospitals constitute the lowest rate of job satisfaction, while the highest one belonged to preventive medicine department. In hospitals, work load especially in emergency rooms (Canadian National physician survey; 2008), mental and physical stress in inpatient departments may explain the lower rate of satisfaction among how in hospitals than that in primary care units and preventive care situations.

The region from where how comes was not significantly associated with job satisfaction which is supporting in selecting hcw from any area in this country. These finding agree with (Bodur; 2002) who stated that work base which how comes from was not significantly associated with job satisfaction in the new settings.

The number of participations was significantly associated with rate of satisfaction. The rate of satisfaction reaches its lowest rate among those who came to Hajj for the first time. This means that satisfaction at work was associated with the level of experience which in accord with available literature (Al-Eisa et al; 2005 and Abdel-Rahman et al; 2008) which revealed increasing rates of satisfaction with the increased years of experience.

Enough compensation and payment for working in hajj were associated with high rate of satisfaction, indicating to the importance financial support which was in accord with many studies (Lehmann et al; 2005 Al-Eisa et al; 2005, Abdel-rahman et al; 2008, Ejaz et al; 2008 and Canadian National physician survey; 2008)

The detected job retention and attraction rate in this study was higher than that 
detected in comparable health care settings (Ruwoldt et al; 2007). In this study, willing to participate next Hajj was used to indicate to the rate of job retention and attraction in Hajj. It was significantly expected to increase in older age groups, non-saudis, high rate of satisfaction and in frequently participating how in Hajj seasons. These findings explain that measurement of the rate of satisfaction is an estimate of job retention and attraction of hew in Hajj.

Conclusion: In conclusion, rate of job satisfaction in hew in hajj was high in comparison to other common health care situations. Job retention rate was accordingly high but lower than satisfaction rate.

Recommendations: Younger, males, saudis, new participants or with lack of previous participations and low paid hew must be targeted by research, training and education to enhance their job satisfaction and job retention before going to work in Hajj.

\section{References:}

1. Abdel-Rahman AG, Abdel Halim AW, Allam MF, Meky F (2008): "Low Job Satisfaction among Physicians in Egypt.” Kor. Hek. 7(2):9196.

2. Al-Eisa IS, Al-Mutar MS, Al-Abduljalil HK (2005): "Job Satisfaction of Primary Health Care Physicians at Capital Health Region, Kuwait.” Middle East J. Family Med. 3 (3): 3- 5.

3. Annual statistical report of Hajj 1428 H (2007 G), Ministry of Health Statistics Department. KSA.
4. Bodur S (2002): "Job satisfaction of health care staff employed at health centers in Turkey." Occup. Med. 52 (6): 353 -5.

5. Canadian National physician survey (2008): "NPS Identifies Urgent Need for a Canadian Physician Workforce Strategy." Media Release Embargoed until Jan 9, 2008 - www.nationalphysiciansurvey.ca

6. Ejaz FK, Noelker LS, Menne HL, Bagaka's JG (2008): "The Impact of Stress and Support on Direct Care Workers' Job Satisfaction." The Gerontologist 48 (Special Issue I): 60-70.

7. Epi info version 6.04d - January (2001): “A Word Processing, Database and Statistics Program for Public Health." World Health Organization. Geneva, Switzerland.

8. Haas JS, Cook EF, Puopolo RL, Burstin HR, Cleary PD, Brennan TA (2000): "Is the professional satisfaction of general internists associated with patient satisfaction?" J. Gen. Intern. Med. 15:122-128.

9. IDAK Group (2005): "IDAK Job Satisfaction Survey."- http://www.idakgroup.com/

10. Jennifer W (2003): "Job stress, poor mental health and education." WebMD Med. News Arch. April 2003: http://content.health.msn. com.

11. Joyce C, Veitch C, Crossland L (2003): "Professional and social support networks of rural general practitioners." Australian J. Rural Health 11:7-14.

12. Kalantan KA, AL-Taweel AA, Abdul Ghani H (1999): "Factors influencing job satisfaction among primary health care (PHC) physicians in Riyadh, Saudi Arabia.” Ann. Saud. Med. 19 (5): $424-6$.

13. Katz A (1999): "Better outcome means more job satisfaction: pilot project in Winnipeg and Halifax to enhance physician-patient communication." Can. Fam. Physician 45:218-220.

14. Lehmann U, Martineau T, Dieleman M, Lexombooon D, Matwa P (2005): "The staffing 
of remote rural health services in low-income countries: a literature review of issues and options affecting attraction and retention." 3rd Public Health Conference 2006, Making Health Systems Work, Midrand, South Africa, 15-17 May 2006.

15. Leigh JP, Kravitz RL, Schembri, MS (2002): "Physician Career Satisfaction across Specialties.” Arch. Intern. Med. 162:1577- 84.

16. Pathman DE, Konrad TR, Williams ES, Scheckler WE, Linzer M, Douglas J (2002): "Physician Job satisfaction, job dissatisfaction, and physician turnover." JFP online July 2002; 51 (7): 593 http://www.jfponline.com/default.asp.
17. Records of human resources working in Hajj (2008): general directorate of hajj services, KSA Ministry of health.

18. Ruwoldt P, Perry S, Yumkella F, Sagoe K (2007): "The Capacity Project and Ghana Ministry of Health Assessment of the Additional Duties Hours Allowance (ADHA) Scheme." Final Report December 2007.

19. Sobreques J, Cebria J, Segura J, Rodriguez C, Garcia M, Juncosa S (2003): Job satisfaction and burnout in general practitioners. Aten. Primaria. 31(4): 227-33.

20. Wetterneck TB, Linzer M, McMurray JE, Douglas J, Schwartz MD, Bigby J, Gerrity MS (2002): "Work life and satisfaction of general internists.” Arch. Intern. Med.162 (6): 649-56. 